\title{
Risk factors and contemporary treatment of orthodontically induced apical root resorption: a
} review

\begin{abstract}
Aim: External apical root resorption is one of the most common side effects of orthodontic treatment. Some amount of root resorption is inevitable in orthodontic. Most of the times root resorption is not severe and goes unnoticed but in few cases root resorption is severe. The cause of root resorption is multifactorial. Aim of this article is to give an insight of root resorption caused by orthodontic tooth movement.
\end{abstract}

Material and method: Articles pertinent to root resorption caused by orthodontic tooth movement were first searched electronically and then hand searched. Relevant article were topic wise critically reviewed by all the reviewers.

Conclusion: It was concluded that many factors are involved in root resorption. In this article possible method of curbing root resorption have also been described.

Keywords: external apical root resorption, osteopontin, rankl, orthodontic treatment, iatrogenic root resorption
Volume 4 Issue 5 - 2016

\author{
Shrish Charan Srivastava,' Ragini Tandon,' \\ Ashish Kakadia,' Kavita Verma ${ }^{2}$ \\ 'Department of Orthodontics and Dentofacial Orthopedics, \\ India \\ ${ }^{2}$ Department of Conservative dentistry and Endodontics, India
}

Correspondence: Shrish Charan Srivastava, Department of Orthodontics and Dentofacial Orthopedics, MDS Orthodontics, Saraswati Dental College Lucknow India, Email drshrish79@rediffmail.com

Received: October 13, 2015 | Published: May 18, 2016
Abbreviations: EARR, external apical root resorption; IL-1A, interlukin 1A; IL-1B, interlukin 1B; LIPUS, low-intensity pulsed ultrasound; PDL, periodontal ligament

\section{Introduction}

External apical root resorption is an unwanted complication of orthodontic treatment which leads to permanent shortening of the roots. There are many reasons attributed to root resorption. Some factors causing root resorption are natural some are pathologic and some are iatrogenic. Orthodontic treatment is one of the main causes for iatrogenic root resorption. Amongst the many factors definitely orthodontic treatment is an important trigger factor for root resorption. ${ }^{1}$ Root resorption can begin in the early leveling stages of orthodontic treatment which can continue throughout the treatment. ${ }^{2}$

Computerized tomography is a superior tool than conventional radiography to estimate root resorption. Conventional radiographic image is a 2D image of 3D object whereas computerized tomography is tool which is capable of giving a 3D image. Computed tomography studies have shown that orthodontically induced root resorption occurs in up to $91 \%$ of teeth. ${ }^{3}$

CBCT is a superior tool to assess root resorption. Whenever patients have a high risk factor for external apical root resorption (EARR) then imaging by CBCT should be done especially when decision has to be taken to modify or terminate the treatment. ${ }^{4}$ Even periapical radiographs may underestimate the actual amount of root resorption when compared to computerized tomography. ${ }^{5}$ Digital Substraction radiography has also been used to estimate the amount of root resorption along with corresponding changes in the bone. ${ }^{6,7}$ The method of Malmgren et al. ${ }^{8}$ has been the gold standard for measurement of root resorption. Scoring system of Malmgren described grade 0 , no root resorption; grade 1, mild resorption, root with a normal length and only displaying an irregular contour; grade 2 , moderate resorption, small area of root loss with the apex exhibiting an almost straight contour; grade 3, accentuated resorption, loss of almost one-third of root length; grade 4, extreme resorption, loss of more than one-third of the root length ${ }^{8,9}$ ( Figure 1).

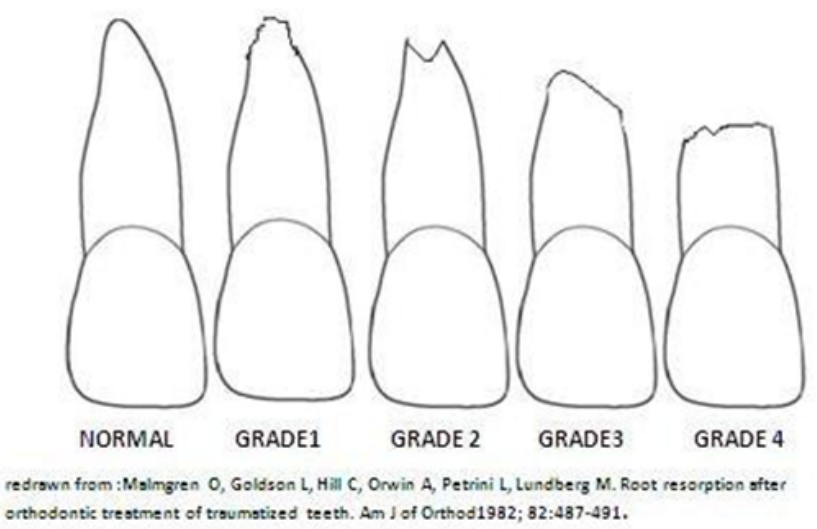

Figure I Grading of root resorption.

\section{Discussion}

There are two types of factors related to external apical root resorption. One is a patient related factor that includes genetics, systemic factors, allergy and asthma. Severity of malocclusion, previous history of root resorption, and root morphology and root proximity with cortical bone also affect root resorption. Other is orthodontic treatment-related risk factors that include the treatment 
duration, magnitude of applied force, direction of tooth movement, amount of apical displacement, and method of force application. ${ }^{10}$ However Taner was not able to establish any significant correlations between the amount of apical root resorption and tooth inclination, and the duration of active treatment. ${ }^{11}$ Roots of maxillay incisors undergo maximum amount of root resorption. The risk of resorption is greatly increased with prolonged treatment time. ${ }^{12}$ Root resorption of maxillary lateral incisors is the second most common to undergo root resorption followed by mandibular lateral incisor. ${ }^{13}$

The incidence of root resorption is almost hundred percent with $1.3 \%$ of cases having severe root resorption exceeding more than $3 \mathrm{~mm} .{ }^{14}$ Brin et al. ${ }^{15}$ reported that the incidence of root resorption was almost equal in teeth with trauma and without trauma. ${ }^{15}$ Severity of apical root resorption does not seem to be affected by gender of the patient. ${ }_{16}$ There is no difference in root resorption in orthodontically treated and endodontically treated teeth. ${ }^{17,18}$

Root of teeth can be of varying shapes like short, blunt, apically bent or pipette shaped. The degree of root resorption with blunt or pipette shaped is significantly higher than normal teeth. ${ }^{19}$ The severity of external apical root resorption is significantly affected by the duration of treatment. Severity of treatment increases with prolonged treatment. ${ }^{20}$

Mean root shortening for the four incisors has been reported to be $0.73 \mathrm{~mm}$ and $0.67 \mathrm{~mm}$ for girls and boys respectively. When using the most severe single root resorption per patient as a parameter the mean was $1.34 \mathrm{~mm}$ for both sexes. ${ }^{21}$ Apical root resorption in orthodontic cases is not affected by the dental invagination and cannot be considered as a risk factor. ${ }^{22}$

External root resorption although inevitable is not influenced by type of appliance. There is no difference in the amount of the root resorption between self ligating brackets and conventional brackets. ${ }^{23,24}$ Lingual orthodontic appliance is also associated with slight periapical root resorption. ${ }^{25}$ Mean root resorption in cases treated with straight wire method (MBT) was $18.26 \%$ compared to $14.82 \%$ in patients treated with standard edgewise appliance. Straight wire patients showed more resorption which could be attributed to more root movement because of built in torque. ${ }^{26,27}$

\section{Genetic factors}

The factors influencing the root resorption due to orthodontic treatment can be broadly divided into genetic and environmental. There is tremendous variation in the severity of root resorption which cannot be explained by environmental factors alone. Genetic factors account for one half to two third of the variation, ${ }^{28}$ (Table 1). Interlukin 1 gene cluster is present on the long arm of chromosome 2 (2q13). It includes 3 genes. Two genes interlukin 1A (IL-1A) and interlukin 1B (IL-1B) encode for pro inflammatory cytokine protein. IL-1B is responsible for the formation of protein IL-1 $\beta$ and IL-1A is responsible for the synthesis of IL- $1 \alpha$.Third gene is IL-RN encodes a related protein Il-1ra. The protein IL-1 $\beta$ has been implicated in bone resorption (catabolic modeling). Allele 2 of IL-1B at +3954 is associated with four fold increase in production of IL-1 $\beta$. In future it will be possible to analyze the DNA from a cheek swab of the patient. The patients having two copies of IL-1B gene would be high risk patients. ${ }^{28-30}$ Variations in the interleukin 1 receptor antagonist gene (rs419598) and the IL1B gene (rs1800587) are determinants of a predisposition to postorthodontic external apical root resorption. ${ }^{31}$
Table I Possible genes involved in eternal apical root resorption

\begin{tabular}{|c|c|c|}
\hline \multicolumn{3}{|c|}{ Possible gene involved in root resorption } \\
\hline & Gene & SNP \\
\hline I & $\begin{array}{l}\text { Interleukin I Receptor } \\
\text { Antagonist Gene }\end{array}$ & rs419598 \\
\hline 2 & $\begin{array}{l}\text { Purinergic-receptor-P2X, } \\
\text { Ligand-gated ion Channel } 7 \\
\text { (P2RX7 }\end{array}$ & rs208294 \\
\hline 3 & Osteopontin Gene & rs9138 and rsII730582 \\
\hline 4 & Interleukin-I $\beta$ Gene & rsII43634 \\
\hline 5 & ILIB Gene & rs1800587 \\
\hline
\end{tabular}

$\mathrm{P} 2 \mathrm{X}$ purinoceptor 7 is a protein that in humans is encoded by theP2RX7 gene. The product of this gene belongs to the family of purinoceptors forATP. P2X7 receptors have been implicated in ATP-mediatedcell death, regulation of receptor trafficking, and inflammation. P2X7 receptor signaling increases the release of proinflammatory molecules such as IL-1 $\beta$, IL-6, and TNF- $\alpha$. Presence of specific genotypes for P2RX7 SNP rs208294 (purinergic-receptorP2X, ligand-gated ion channel 7 (P2RX7; rs208294,) were significantly associated with external apical root resorption (EARR). ${ }^{32,33}$

Genetic variants of the interleukin-1 gene cluster (IL1) are associated with a possible genetically induced variability in postorthodontic external apical root resorption (EARR) in root filled teeth and their control counterparts with vital pulps Genetic variations in the interleukin-1 $\beta$ gene (rs1143634) predispose root filled teeth to EARR. $^{34}$

The main focus of the present study is to clarify whether variants in the interleukin-1 receptor antagonist gene coding for the IL1ra protein have both positive and negative effect on EARR of endodontically-treated teeth. Variants in allele 1 of the interleukin-1 receptor antagonist gene (rs419598) are associated with a high risk of suffering post-orthodontic EARR in endodontically treated teeth. ${ }^{35}$

Non-parametric sibling pair linkage analysis identified evidence of linkage of EARR affecting the maxillary central incisor with the microsatellite marker D18S64 (tightly linked to TNFRSF11A). This indicates that the TNFRSF11A locus, or another tightly linked gene, is associated with EARR. ${ }^{36}$ Osteopontin gene is an essential mediator in the odontoclast fusion and attachment process. Variations in the osteopontin gene (rs9138 and rs11730582) are determinants of a genetic predisposition to suffer EARR secondary to orthodontic treatment. ${ }^{37}$ During orthodontic tooth movement RANKL expression is induced on the compressed side of the tooth. RANKL activates osteoclastogenesis, and this is better demonstrated by the acceleration of tooth movement, which is achieved after transfer of the RANKL gene to the periodontal tissue. ${ }^{38}$

T-lymphocytes secrete soluble s-RANKL. RANKL mRNA is expressed mostly in bone and bone marrow, as well as in lymphoid tissues. The role of RANKL, together with another very important protein ligand, MCSF (which binds to its receptor c-fms), promotes osteoclast formation, fusion, differentiation, activation and survival, thus enhancing bone resorption. The effects of RANKL are produced when it binds to RANK. The biological effects of OPG are opposite to the RANKL-mediated effects, because OPG acts as a soluble receptor antagonist, which competes with RANKL and therefore prevents RANKL-RANK interaction, ${ }^{39}$ (Figure 2). 


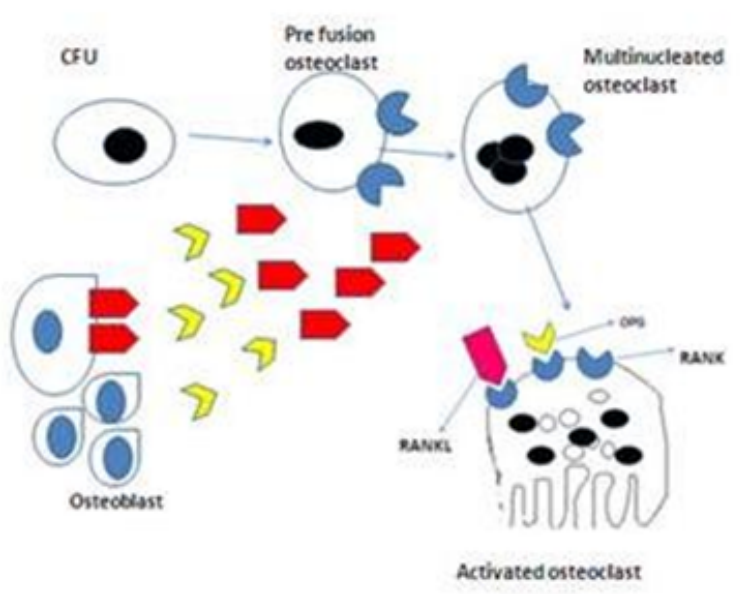

Figure 2 Rank rankl Interaction for osteoclast differentiation.

The resorptive activity of osteoclasts, induced by soluble RANKL or cell-bound RANKL, is completely inhibited by the simultaneous addition of OPG. Conclusively, OPG, RANKL and RANK form a key network that regulates bone metabolism and osteoclast biology RANKL to OPG ratio in periodontal ligament (PDL) cells contribute to root resorption during orthodontic tooth movement. The compressed PDL cells in cases of severe external apical root resorption produce a large amount of RANKL and increases osteoclastogenesis. This explains why there is greater increase of RANKL and decrease of OPG in cases of severe root resorption. ${ }^{40,41}$

\section{Repair}

It has been reported that repair of denuded root takes place after the active force has been removed. The repair takes predominantly by the formation of secondary cemetum. The amount of secondary cementum formed is about three times more after 8 weeks than at 1 week. ${ }^{42}$ Macrophages are large cells and are important mediators of inflammation. There are two types of macrophages which are involved in the inflammatory process. The macrophages which encourage inflammation are called $\mathrm{M} 1$ and those that decrease inflammation and promote tissue repair are called M2.M1 macrophage metabolize arginine to nitric oxide whereas M2 macrophage convert it into repair molecule ornithine. During active treatment M1 macrophages are upregulated on the compression side when the forces are removed then M2 macrophages are upregulated. Root resorption is aggravated by an enhanced M1/M2 ratio and partially rescued by a reduced M1/ M2 ratio. ${ }^{43,44}$

Patients at risk of severe apical root resorption can be identified during the initial treatment stages. It advisable to take periapical $\mathrm{X}$ rays at frequent intervals in high risk patients to determine progress of resorption. ${ }^{45}$ Pressure causes resorption of root but the resorption in such case does not show any radiolucency and the tooth is mostly asymptomatic or associated with mild pain. Root resorption due to pulp pathology will have periapical radiolucency and tooth will be tender on percussion. Root resorption is almost unavoidable in orthodontic patients as such. It needs to be a part of the informed consent process. Root resorption seen due to orthodontic treatment is rarely detrimental and it should be explained to the patient before informed consent.

\section{Drugs}

Many drugs effect induced root resorption (Table 2). Corticosteroids are compounds that are derieved from cholesterol and have widespread effects on various organs. Synthetic steroids are used as anti-inflammatory and immunosuppressive agents in the treatment of wide range of chronic and medical condition. Prednisolone is a moderately potent synthetic steroid which has been used in animals and humans to study the effects of steroids. Prolonged administration of synthetic corticosteroids is associated with bone loss and osteoporosis. In low dose prednisolone has been associated with decrease in bone resorption. In animal studies prednisolone has shown to reduce resorption by suppressing the inflammation and clastic activity. ${ }^{46}$

Table 2 Possible role of drugs in controlling root resorption

Possible role of drugs in controlling root resorption.

\begin{tabular}{|c|c|c|}
\hline & Name & Group \\
\hline 1 & Prednisolone & Corticosteroid \\
\hline 2 & L- thyroxine & Hormone \\
\hline 3 & Celebrex & $\begin{array}{l}\text { Nonsteroidal Anti-inflammatory Cox } 2 \\
\text { Inhibitor }\end{array}$ \\
\hline 4 & Clodronate & Bisphosphonates \\
\hline 5 & Doxycyclin & Broad spectrum Antimicrobial Agent \\
\hline
\end{tabular}

Administration of prednisolone and high-dose celecoxib reduces root resorption and interferes with tooth movement in rats. Both drugs may interfere in the arachidonic acid cascade depending on dose thresholds. L- thyroxine decreased the exent of root resorption while increasing the amount of tooth movement. Administration of Celebrex during the application of orthodontic forces does not interfere with tooth movement and appears to offer some slight protection against root resorption. ${ }^{47}$ The short and long-term celecoxib administration did not suppress the root resorption in case of experimental orthodontic force application. ${ }^{48}$

Systemic administration of low-dose doxycyclin in rats have an inhibits orthodontically induced resorptive activity to some extent. ${ }^{49,50}$ A histological section observed under scanning electron microscope has confirmed that root resorption lacunae decrease on aministration of thyroxine..$^{51}$ Doxycyclin is a potent antimicrobial agent has been shown to have some anti inflammatory effect. Doxycyclin reduces the resorption by directly inhibiting the osteoclasts. ${ }^{52,53}$ Doxycyclin inhibits the orthoclastic activity that is not related to infectious agents. The reduction in orthoclastic activity is due to apoptosis of osteoclast. Low dose of doxycyclin may be useful in to controlling root resorption clinically. ${ }^{54,55}$

Bisphosphonates are a class of drugs that prevent the loss of bone mass, used to treat osteoporosis and similar diseases. They are the most commonly prescribed drugs used to treat osteoporosis. Local application of riserdronate in rats arrests root resorption. ${ }^{56,57}$ Similarly Clodronate, a non-N-containing bisphosphonate, inhibits bone resorption and also has anti-inflammatory properties .Localized use of clodronate could be a useful in orthodontic treatment. ${ }^{58}$ Root resorption also occurs in reimplanted teeth. Soaking the teeth in alandronate solution rather than Hanks Balanced salt solution reduces the chance of root resorption. ${ }^{59}$ 


\section{Low intensity pulsed ultra sound}

Low intensity pulsed ultrasound can enhance healing of connective tissue and dental tissue and has some benefit in cases of root resorption. ${ }^{60}$ Low intensity pulsed ultrasound has a beneficial effect on fracture healing. Complex cellular reaction takes place in bone healing. Some of these processes are accelerated by low intensity pulsed ultra sound. Cells like fibroblast, chondrocytes osteoblast and osteocytes are mechnosenstive cells are affected by low intensity ultrasound. Low-intensity pulsed ultrasound acts on osteoblastic cells at a specific stage of differentiation and induces direct anabolic reactions, which results in bone matrix formation. ${ }^{61-63}$ Effect of lowintensity pulsed ultrasound (LIPUS) on orthodontically induced root resorption .The LIPUS-, decreases osteoclast numbers and activity levels, and increased OPG/RANKL expression ratios. ${ }^{64}$

\section{Effect of force and endodontic treatment on root resorption}

Rey et al. ${ }^{65}$ have suggested that orthodontic management of external apical root resorption should be done by simple mechanical techniques. Light and controlled forces, allowing predictable movements which are physiologically acceptable. Prevention of root resorption can occur by application of light and controlled forces. ${ }^{65}$

Teeth with only the cervical third remaining from orthodontically induced external root resorption must remain in one's mouth with function and esthetics preserved. In these cases, endodontic treatment is not recommended for affected teeth because the pulp is not involved in the process and the post-treatment phase of endodontic therapy might be a complicating factor due to risks of accidental contamination or filling material overflow. ${ }^{66}$

The resorption and repair processes during the early stages of retention are balanced, and most of the reparative process occurs after 4 weeks of passive retention after the application of orthodontic force. Frequent orthodontic reactivations should be avoided to promote recovery and repair of root surface damage. ${ }^{67}$ Kheirieh et al. ${ }^{68}$ reported a case where they did extraoral retrograde root canal filling with CEM cement in a refractory apical lesion due to orthodontically induced extensive EARR. ${ }^{68}$

Orthodontic treatment is frequently related to the occurrence of apical root resorption. The concentration of orthodontic forces on the root, especially on the apex, can cause biological changes in the cementum and periodontal ligament, resulting in root resorption. ${ }^{69,70}$ Intrusion of incisor creates considerable amount of stress at the apex and is associated with greatest amount of root resorption. Comparable resorption is seen with anterior retraction..$^{71-75}$

Resorptive activity is more pronounced after the heavy forces. The reparative processes are different between the light and heavy forces, with marked individual variations. Repair becomes steady after 4 weeks of passive retention following 4 weeks of light force application, whereas most repair occurs after 4 weeks of passive retention following 4 weeks of heavy force application. Root resorption crater volume positively depended on tooth movement and negatively correlated with chronologic age. ${ }^{76}$ The volume of root resorption craters formed by buccally directed forces for 12 weeks on the maxillary and mandibular first premolars are directly proportional to the magnitude of the force. ${ }^{77}$

\section{Conclusion}

Root resorption is almost always associated with orthodontic treatment. At present our understanding about orthodontically induced root resorption is limited. Drugs like doxycyclin and bisphosphonate may be used in future to arrest root resorption. Low intensity ultrasound also has reparative effect on induced root resorption.

\section{Funding}

None.

\section{Acknowledgements}

None.

\section{Conflicts of interest}

The author declares there are no conflicts of interest.

\section{References}

1. Weltman B, Vig KW, Fields HW, et al. Root resorption associated with orthodontic tooth movement: a systemic review. Am J Orthod Dentofacial Orthop. 2010;137(4):426-476.

2. Smale I, Artun J, Behbehani F, et al. Apical root resorption 6 months after initiation of fixed orthodontic appliance therapy. Am J Orthod Dentofacial Orthop. 2005;128(1):57-67.

3. Lund H, Grondahl, Hansen K, et al. Apical root resorption during orthodontic treatment; A prospective study using cone beam CT. Angle Orhtod. 2012;82(3):480-487.

4. Dudic A, Giannopoulou C, Leuzinger M, et al. Detection of apical root resorption after orthodontic treatment by using panoramic radiography and cone beam computed tomography of super high resolution. Am J Orthod Dentofacial Orthop. 2009;135(4):434-437.

5. Dudic A, Giannopoulou C, Martinez M, et al. Diagnostic accuracy of digitized periapical radiographs validated against micro-coputed tomography scanning in evaluating orthodontically induced apical root resorption. Eur J Oral Sci. 2008;116(5):467-472.

6. Sunku R, Roopesh R, Kancherla KK, et al. Quantitative digital subtraction radiography in assessment of external apical root resorption induced by orthodontic therapy: a retrospective study. J Contemp. Dent Pract. 2011;12(6):422-428.

7. Loannidou-Marathiotou I, Papadopoulos MA, Kondylidou-Sidira A, et al. Digital Subtraction radiography of panoramic radiographs to evaluate maxillary central incisor root resorption after orthodontic treatment. World J Orthod. 2010;11(2):142-152.

8. Malmgren O, Goldson L, Hill C, et al. Root resorption after orthodontic treatment of traumatized teeth. Am J of Orthod. 1982;82(6):487-491.

9. Zahrowski J, Jeske A. Apical root resorption is associated with comprehensive orthodontic treatment but not clearly dependent on prior tooth characteristics or orthodontic techniques. J Am Dent Assoc. 2011;142(1):66-68.

10. Topkara A, Karaman AI, Kau CH. Apical root resorption caused by orthodontic forces: A brief review and a long-term observation. Eur J Dent. 2012;6(4):445-453.

11. Taner T, Ciger S, Sencift Y. Evaluation of apical root resorption following extraction therapy in subjects with Class I and Class II malocclusion. Eur J Orthod. 1999;21(5):491-496. 
12. Apajalahti S, Peltola JS. Apical root resorption after orthodontic treatment- a retrospective study. Eur J Orthod. 2007;29(4):408-412.

13. Maues CP, Nascimento RR, Viella Ode. Severe root resorption resulting from orthodontic treatment: prevelance and risk factor. Dental Press $J$ Orhtod. 2005;20(1):52-58.

14. Owman-Moll P, Kurol J. Root resorption after orthodontic treatment in high and low risk patients: analysis of allergy as a possible predisposing factor. Eur J Orthod. 2000;22:657-663.

15. Brin T, Tulloch JF, Koroluk L, et al. External apical root resorption in class II malocclusion: a retrospective review of 1-versus 2 phase treatment. $\mathrm{Am}$ J Orthod Dentofacial Orthop. 2003;124(2):151-156.

16. Nigul K, Jagomagi T. Factors related to apical root resorption of maxillary incisor in orthodontic patients. Stomatologija. 2006;8(3):76-79.

17. Llamas-Carreras JM, Amarilla A, Espinar-Escalona E, et al. Externa apical root resorption in maxillary root-filled incisor after orthodontic treatment: A split mouth design. Study Med Oral Patol Oral Cir Bucal. 2012;17(3):e523-e527.

18. Llamas-Carreras JM, Amarilla A, Solano E, et al. Study of external root resorption during orthodontic treatment in root filled teeth compared with their contralateral teeth with vital pulps. Int Endod J. 2010;43(8):624 662 .

19. Levander E, Malmgren O. Evaluation of risk of root resorption during orthodontic treatment: a study of upper incisor. Eur J Orthod. 1988;10(1):30-38

20. Nanekrungsan K, Patanaporn V, Janhom A, et al. External apical roo resorption in maxillary incisor in orthodontic patients: associated factors and radiographic evaluation. Imaging Sci Dent. 2012;42(3):147-154.

21. Linge BO, Linge L. Apical root resorption in upper anterior teeth. Eur $J$ Orthod. 1983;5(3):173-183.

22. Mavragni M Apisariyakul J, Brudvik P, Selvig KA. Is mild dental invagination a risk factor for apical root resorption in orthodontic patients? Eur J Orthod. 2006;28(4):307-312.

23. Leite V, Conti AC, Navarro R, et al. Comparison of root resorption between self-ligating and conventional preadjusted brackets using cone beam computed tomography. Angle Orthod. 2012;82(6):1078-1082.

24. Pandis N, Nasika M, Polychronopoulou A, et al. External apical root resorption in patients treated with conventional and self-ligating brackets. Am J Orthod Dentofacial Orthop. 2008;134(5):646-651.

25. Fritz U, Diedrich $P$, Wiechmann D. Apical root resorption after lingua orthodontic therapy. J Orofac Orthop. 2003;64(6):434-442.

26. Zahed Zahedani S, Oshagh M, Momeni Danaei Sh, et al. A Comparison of pical Root Resorption in Incisors after Fixed Orthodontic Treatment with Standard Edgewise and Straight Wire (MBT) Method. J Dent (Shiraz). 2013;14(3):103-110.

27. Mavragani M, Vergari A, Selliseth NJ, et al. A radiographic comparison of apical root resorption after orthodontic treatment with a standard edgewise and a straight-wire edgewise technique. Eur J Orthod. 2000;22(6):665674.

28. Hartsfield JK. Pathways in external apical root resorption associated with orthodontia. Orthod Craniofac Res. 2009;12(3):236-242.

29. Al-Qawasmi RA, Hartsfield JK, Everett ET, et al. Genetic predisposition to external apical root resorption. Am J Orthod Dentofacial Orthop. 20003;123(3):242-252.

30. Bastos Lages EM, Drummond AF, Pretti H, et al. Association of functional gene polymorphism IL-1beta in patients with external apical root resorption. Am J Orthod Dentofacial Orthop. 2009;136(4):542-546.
31. Iglesias-Linares A, Yañez-Vico R, Ballesta-Mudarra $\mathrm{S}$, et al. Postorthodontic external root resorption is associated with IL1 receptor antagonist gene variations. Oral Dis. 2012;18(2):198-205.

32. Sharab LY, Morford LA, Dempsey J, et al. Genetic and treatment-related risk factors associated with external apical root resorption (EARR) concurrent with orthodontia. Orthod Craniofac Res. 2015;18(1):71-82.

33. PG and RANK in orthodontic-induced apical root resorption. Oral Dis. 2014;20(7):659-667.

34. Iglesias-Linares A, Yañez-Vico RM, Ballesta S, et al. Interleukin 1 gene cluster SNPs (rs1800587, rs1143634) influences post-orthodontic root resorption in endodontic and their contralateral vital control teeth differently. Int Endod J. 2012;45(11):1018-1026.

35. Iglesias-Linares A, Yañez-Vico RM, Ballesta-Mudarra S, et al. Interleukin 1 receptor antagonist (IL1RN) genetic variations condition post-orthodontic external root resorption in endodontically-treated teeth. Histopathol. 2013;28(6):767-773.

36. Al-Qawasmi RA, Hartsfield JK, Everett ET, et al. Genetic predisposition to external apical root resorption in orthodontic patients: linkage of chromosome-18 marker. J Dent Res. 2003;82(5):356-360.

37. Iglesias-Linares A, Yañez-Vico RM, Moreno-Fernández AM, et al Osteopontin gene SNPs (rs9138, rs11730582) mediate susceptibility to external root resorptionin orthodontic patients. Oral Dis. 2014;20(3):307312 .

38. Kanzaki H, Chiba M, Arai K, et al. Local RANKL gene transfer to the periodontal tissue accelerates orthodontic tooth movement. Gene Ther. 2006;13(8):678-685.

39. Kwon BS, Wang S, Udagawa N, et al. A new member of the tumor necrosis factor receptor family induces fibroblast proliferation and inhibits osteoclastogenesis and bone resorption. FASEB J. 1998;12(10):845-854.

40. Nishijima Y, Yamaguchi M, Kojima T, et al. Levels of RANKL and OPG in gingival crevicular fluid during orthodontic tooth movement and effect of compression force on releases from periodontal ligament cells in vitro. Orthod Craniofacial Res. 2006;9(2):63-70.

41. Kanzaki H, Chiba M, Shimizu Y, et al. Periodontal ligament cells under mechanical stress induce osteoclastogenesis by receptor activator of nuclear factor kappa-B ligand up-regulation via prostaglandin E2 synthesis. J Bone Miner Res. 2012;17(1):210-220.

42. Owman-Moll P. Orthodontic tooth movement and root resorption with special reference to force magnitude and duration. A clinical and histological investigation in adolescents. Swed Dent J Suppl. 1995;105:145 .

43. He D, Kou X, Luo Q, et al. Enhanced M1/M2 macrophage ratio promotes orthodontic root resorption. J Dent Res. 2015;94(1):129-139.

44. Zhou D, Huang C, Lin Z, et al. Macrophage polarization and function with emphasis on the evolving roles of coordinated regulation of cellular signaling pathways. Cell Signal. 2014;26(2):192-197.

45. Artun J, Van't Hullenaar R, Doppel D, et al. Identification of orthodontic patients at risk of severe apical root resorption. Am J Orthod Dentofacial Orthop. 2009;135(4):448-455.

46. Ong CK, Walsh LJ, Harbrow D, et al. Orthodontic Tooth Movement in the Prednisolone-Treated Rat. The Angle Orthod. 2009;70(2):118-125.

47. Jerome J, Brunson T, Takeoka G, et al. Celebrex offers a small protection from root resorption associated with orthodontic movement. J Calif Dent Assoc. 2005;33(12):951-959.

48. Gameiro GH, Nouer DF, Pereira-Neto JS, et al. Histological analysis of orthodontic root resorption in rats treated with the cyclooxygenase-2 (COX-2) inhibitor celecoxib. Orthod Craniofac Res. 2008;11(3):156161. 
49. Mavragani M, Brudvik P, Selvig KA. Orthodontically induced root and alveolar bone resorption: inhibitory effect of systemic doxycycline administration in rats. Eur J Orthod. 2005;27(3):215-225.

50. Seifi M, Hamedi R, Khavandegar Z. The Effect of Thyroid Hormone, Prostaglandin E2, and Calcium Gluconate on Orthodontic Tooth Movement and Root Resorption in Rats. J Dent (Shiraz). 2015;16(1):35142 .

51. Shirazi M, Dehpour AR, Jafari F. The effect of thyroid hormone on orthodontic tooth movement in rats. J Clin Pediatr Dent. 1999;23(3):259 264.

52. Mavragani M, Brudvik P, Selvig KA. Orthodontically induced roo and alveolar bone resorption: inhibitory effect of systemic doxycycline administration in rats. Euro J Orthod. 2005;27(3):215-225.

53. Gonzales C, Hotokezaka H, Matsuo K, et al. Effects of steroidal and Nonsteroidal drugs on tooth movement and root resorption in the rat molar. Angle Orthod. 2009;79(4):715-726.

54. Bezerra MM, Brito GA, Ribeiro RA, et al. Low-dose doxycycline prevents inflammatory bone resorption in rats. Braz J Med Biol Res. 2002;35(5):613-616.

55. Bettany JT, Peet NM, Wolowacz RG, et al. Tetracyclines induce apoptosis in osteoclasts. Bone. 2000;27(1):75-80.

56. Igarashi $\mathrm{K}$, Adachi H, Mitani H, et al. Inhibitory Effect of the Topical Administration of a Bisphosphonate (Risedronate) on Root Resorption Incident to Orthodontic Tooth Movement in Rats. JDR. 19996;75(9):1644 1649.

57. Adachi H, Igarashi K, Mitani H, et al. Effects of Topical Administration of a Bisphosphonate (Risedronate) on Orthodontic Tooth Movements in Rats. J DENT RES. 1994;73(8):1478-1486.

58. Liu L, Igarashi K, Haruyama N, et al. Effects of local administration of clodronate on orthodontic tooth movement and root resorptionin rats. Eur J Orthod. 2004;26(5):469-473.

59. Levin L, Bryson EC, Caplan D, et al. Effect of topical alendronate on root resorption of dried replanted dog teeth. Dent Traumatol. 2001;17(3):120126.

60. El-Bialy T, El-Shamy I, Graber TM. Repair of orthodontically induced root resorption by ultrasound in humans. Am J Orthod and Dentofacial Orthop. 2004;126(2):186-193.

61. Naruse K, Mikuni-Takagaki Y, Azuma Y, et al. Anabolic response of mouse bone-marrow-derived stromal cell clone ST2 cells to low-intensity pulsed ultrasound. Biochem Biophys Res Commun. 2000;268(1):216-220.

62. Naruse K, Miyauchi A, Itoman M, et al. Distinct anabolic response of osteoblast to low-intensity pulsed ultrasound. J Bone Miner Res. $2003 ; 18(2): 360-369$

63. Ikai H, Tamura T, Watanabe T, et al. Low-intensity pulsed ultrasound accelerates periodontal wound healing after flap surgery. Journal of Periodontal Research. 2008;43(2):212-216.
64. Liu Z, Xu J, E L, et al. Ultrasound enhances the healing of orthodontically induced root resorption in rats. Angle Orthod. 2012;82(1):48-55.

65. Rey D, Smit RM, Gamboa L. Orthodontic treatment in patient with idiopathic root resorption: a case report. Dental Press J Orthod. 2015;20(1):108-117.

66. Consolaro A, Furquim LZ. Extreme root resorption associated with induced tooth movement: a protocol for clinical management. Dental Press J Orthod. 2014;19(5):19-26.

67. Gonzales C, Hotokezaka H, Darendeliler MA, et al. Repair of root resorption 2 to 16 weeks after the application of continuous forces on maxillary first molars in rats: a 2- and 3-dimensional quantitative evaluation. Am J Orthod Dentofacial Orthop. 2010;137(4):477-485.

68. Kheirieh S, Fazlyab M, Torabzadeh H, et al. Extraoral Retrograde Root Canal Filling of an Orthodontic-induced External Root Resorption Using CEM Cement. Iran Endod J. 2014;9(2):149-152.

69. George A, Evans CA. Detection of root resorption using dentin and bone markers. Orthod Craniofac Res. 2009;12(3):229-235.

70. Brezniak N, Wasserstein A. Root resorption after orthodontic treatment: Part 1. Literature review. American Journal of Orthodontics and Dentofacial Orthopedics. 1993;103:62-66.

71. Faltin RM, Faltin K, Sander FG, et al. Ultrastructure of cementum and periodontal ligament after continuous intrusion in humans: a transmission electron microscopy study. Eur J Orthod. 2001;23(1):35-49.

72. McFadden WM, Engstrom C, Engstrom H, Anholm JM. A study of the relationship between incisor intrusion and root shortening. Am J of Orthod and Dentofacial Orthop. 1989;96(5):390-396.

73. McNab S, Battistutta D, Taverne A, et al. External apical root resorption following orthodontic treatment. Angle Orthod. 2000;70(3):227-232.

74. Mirabella AD, Artun J. Risk factors for apical root resorption of maxillary anterior teeth in adult orthodontic patients. Am J of Orthod and Dentofacial Orthop. 1995;108(1):48-55.

75. Martins DR, Tibola D, Janson G, et al. Effects of intrusion combined with anterior retraction on apical root resorption. Eur J Orthod. 2012;34(2):170-175.

76. Cheng LL, Türk T, Elekdağ-Türk S, et al. Physical properties of root cementum: Part 13. Repair of root resorption 4 and 8 weeks after the application of continuous light and heavy forces for 4 weeks: a micro computer-tomography study. Am J Orthod Dentofacial Orthop. 2009;136(3):320.e1-10.

77. Paetyangkul A, Türk T, Elekdağ-Türk S, et al. Physical properties of root cementum: part 14. The amount of root resorption after force application for 12 weeks on maxillary and mandibular premolars: a micro computertomography study. Am J Orthod Dentofacial Orthop. 2009;136(4):492. 